\title{
Modelling of the effects of grain orientation on transformation-induced plasticity in multiphase carbon steels
}

\author{
D D Tjahjanto ${ }^{1}$, S Turteltaub, A S J Suiker and S van der Zwaag \\ Faculty of Aerospace Engineering, Delft University of Technology, Kluyverweg 1, 2629 HS \\ Delft, The Netherlands \\ E-mail: d.d.tjahjanto@1r.tudelft.nl
}

Received 14 October 2005, in final form 27 March 2006

Published 28 April 2006

Online at stacks.iop.org/MSMSE/14/617

\begin{abstract}
The effects of grain orientation on transformation-induced plasticity in multiphase steels are studied through three-dimensional finite element simulations. The boundary value problems analysed concern a uniaxiallyloaded sample consisting of a grain of retained austenite surrounded by multiple grains of ferrite. For the ferritic phase, a rate-dependent crystal plasticity model is used that describes the elasto-plastic behaviour of body-centred cubic crystalline structures under large deformations. In this model, the criticalresolved shear stress for plastic slip consists of an evolving slip resistance and a stress-dependent term that corresponds to the projection of the stress tensor on a non-glide plane (i.e. a non-Schmid stress). For the austenitic phase, the transformation model developed by Turteltaub and Suiker (2006 Int. J. Solids Struct. at press, 2005 J. Mech. Phys. Solids 53 1747-88) is employed. This model simulates the displacive phase transformation of a face-centred cubic austenite into a body-centred tetragonal martensite under external mechanical loading. The effective transformation kinematics and the effective anisotropic elastic stiffness components in the model are derived from lower-scale information that follows from the crystallographic theory of martensitic transformations. In the boundary value problems studied, the mutual interaction between the transforming austenitic grain and the plastically deforming ferritic matrix is computed for several grain orientations. From the simulation results, specific combinations of austenitic and ferritic crystalline orientations are identified that either increase or decrease the effective strength of the material. This information is useful to further improve the mechanical properties of multiphase carbon steels. In order to quantify the anisotropic
\end{abstract}

1 Author to whom any correspondence should be addressed. 
aspects of the crystal plasticity model, the simulation results for the uniaxiallyloaded sample are compared with those obtained with an isotropic plasticity model for the ferritic grains.

\section{Introduction}

Transformation-induced plasticity (TRIP) steels are a class of multiphase carbon steels that possess both good strength and good ductility properties. A typical TRIP steel microstructure consists of ferrite as the dominant phase, retained austenite (RA), bainite and occasionally small fractions of thermal martensite. The stability of RA at room temperature is provided through a controlled thermal processing route to carbon-enrich the austenite and the addition of alloying elements such as silicon and aluminium to suppress cementite formation, as well as through the constraining effect of the surrounding phases $[3,4]$. When subjected to mechanical loading, the RA may transform into martensite, which is a relatively hard phase that generally increases the overall strength of the TRIP steel. The shape and volume changes that characterize this transformation are typically accommodated by plastic deformations in the surrounding phases (mainly ferrite) and are associated with good macroscopic strength-ductility combinations. However, further improvement in the mechanical properties of these multiphase carbon steels is necessary in order to retain a competitive position in relation to high-quality non-ferrous alloys or other high-performance steel grades.

Over the past 15 years, several constitutive models were developed for the analysis of the TRIP effect in metals [2,5-12]. However, in most of these models the elasto-plastic deformation induced by the transformation is simplified through an isotropic model. The assumption of an isotropic elasto-plastic behaviour is in general inaccurate at the scale of observation where the interaction of individual single-crystal grains is considered. The use of a continuum crystal plasticity theory, which takes into account anisotropic effects related to the crystallographic lattice orientation of the grains, is therefore more appropriate. The present paper aims at elucidating the influence of the orientation of ferritic and austenitic grains on the TRIP effect in multiphase carbon steels. For this purpose, three-dimensional finite element analyses are carried out on uniaxially-loaded samples comprising a grain of RA surrounded by either one or multiple grains of ferrite. The anisotropic elasto-plastic behaviour of the ferrite grains is simulated through a crystal plasticity model and the anisotropic transformation behaviour in the RA grains is simulated via the martensitic transformation model of Turteltaub and Suiker [1,2]. The combination of these models enables us to study the role of microstructural texture on the overall response of TRIP steel samples and thus provides a design tool for optimizing the mechanical properties of these materials.

A rate-dependent kinetic formulation is adopted in the crystal plasticity model, which quantifies the relation between the rate of plastic slip and the energetically conjugated driving force. The driving force for plastic slip is equal to the classical Schmid stress (or resolved shear stress), which corresponds to the shear stress component acting on the actual slip plane and along the slip direction. The kinetic law also includes the critical-resolved shear stress necessary for activating slip, which is determined by the evolving slip resistance at the actual slip plane and a 'non-Schmid stress' contribution associated with a non-glide plane. The evolution of the slip resistance is defined by a phenomenological hardening law, which comprises the mechanisms of self-hardening and cross-hardening. The non-Schmid stress accounts for the fact that the core of screw dislocations in body-centred cubic (BCC) metals spreads into three $\{110\}$ planes intersecting along the $\langle 111\rangle$ slip directions [13]. 
The microstructural basis of the martensitic phase transformation model of Turteltaub and Suiker [1,2] stems from the crystallographic theory of martensitic transformations originally developed by Wechsler et al [14] and further refined by Ball and James [15]. The facecentred cubic (FCC) austenite transforms into one or several of the possible 24 transformation systems, where a transformation system is characterized as a special arrangement of twinned body-centred tetragonal (BCT) martensite with a specific orientation. Lower-scale information related to the geometry and orientation of the martensitic transformation systems is used to construct the effective anisotropic elasticity tensor at the grain level.

The paper is organized as follows: the crystal plasticity model for BCC ferrite is outlined in section 2. Subsequently, we discuss the kinematic assumptions, the driving force for plastic deformation, the constitutive model, the kinetic relation and the evolution of the slip resistance. In a similar fashion, the martensitic transformation model of Turteltaub and Suiker $[1,2]$ is summarized in section 3 . In section 4 , we discuss the numerical simulations of several TRIP microstructures subjected to uniaxial tension. Finally, some concluding remarks are given in section 5 .

As a general scheme of notation, scalars are written as lightface italic letters, vectors as boldface lowercase letters (e.g. a, b), second-order tensors as boldface capital letters (e.g. A, B) and fourth-order tensors as blackboard bold capital letters (e.g. $\mathbb{A}, \mathbb{B}$ ). The action of a second-order tensor upon a vector is denoted as $\mathbf{A} \mathbf{b}$ and the action of a fourth-order tensor upon a second-order tensor is designated as $\mathbb{A} \mathbf{B}$. Composition of two second-order tensors is denoted as $\mathbf{A} \mathbf{B}$. The tensor product between two vectors is denoted as $\mathbf{a} \otimes \mathbf{b}$. All inner products are indicated by a single dot in between tensorial quantities of the same order (e.g. $\mathbf{a} \cdot \mathbf{b}$, A $\cdot \mathbf{B})$. Latin superindices in parentheses are used for slip systems while Greek superindices in parentheses refer to transformation systems. Additional notations will be introduced where required.

\section{Crystal plasticity model for $\mathrm{BCC}$ ferrite}

A basic feature of rate-independent crystal plasticity models relies on the assumption that gliding along an individual slip system is determined by the classical Schmid's law, in which the Schmid stress (or resolved shear stress) is equated with the evolving slip resistance of the slip system. Although this assumption is reasonable for close-packed crystals such as in FCC metals, it cannot be directly applied to BCC crystals. Atomistic simulations on BCC crystals performed by Duesbery and Vitek [16] have shown that plastic deformations of BCC metals are governed by the movement of $1 / 2\langle 111\rangle$ screw dislocations with cores spreading into three $\{110\}$ planes intersecting along the $\langle 111\rangle$ slip directions. The non-planar spreading of the dislocation core causes the slip along an individual plane of the $\{110\}$ class to become dependent on shear stresses acting on another $\{110\}$ plane of the [111] zone, called a 'non-glide plane'. The stresses acting on the non-glide plane, called non-Schmid stresses, can be included in a crystal plasticity modelling framework through a modification of the classical Schmid's law, as proposed by Bassani et al [17]. Although the non-glide stress model was originally derived from atomistic simulations of BCC molybdenum and tantalum, it is assumed in the present work that the plastic slip in BCC ferrite can be described by a similar mechanism. This assumption is reasonable since the ferritic lattice shares the same generic features with the lattices of molybdenum and tantalum, namely the asymmetry of slips in the twinning and antitwinning directions [18]. A validation of this assumption would require atomistic simulations of BCC ferrite; however, these fall outside the scope of the present work.

Plastic slip in BCC crystals operates through the propagation of screw dislocations along the $\langle 111\rangle$ directions. Because of a lack of close-packed planes in a BCC crystalline structure, 


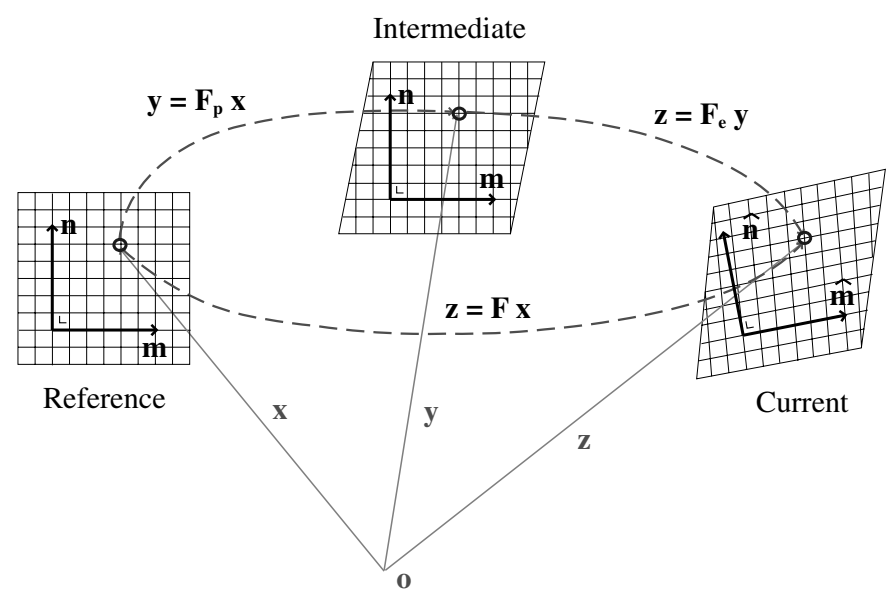

Figure 1. Schematic representation of the decomposition of deformation gradient $\boldsymbol{F}$ into a plastic part $\boldsymbol{F}_{\mathrm{p}}$ and an elastic part $\boldsymbol{F}_{\mathrm{e}}$. The vectors $\boldsymbol{m}$ and $\boldsymbol{n}$ are, respectively, the slip direction and slip plane normal in the reference and intermediate configurations, while vectors $\hat{\boldsymbol{m}}$ and $\hat{\boldsymbol{n}}$ are the corresponding vectors in the current configuration.

there is no clear consensus among researchers on which planes slip occurs. Experimental observations often indicate slip traces along $\{110\},\{211\}$ and $\{321\}$ planes, as well as along non-crystallographic planes. However, high resolution micrographs show that in BCC crystals slip on $\{321\}$ and higher index planes appears in small wavy patterns, which can be interpreted as slip composed of alternating glide contributions along lower index planes [19,20]. Recent atomistic simulations by Bassani et al [17] indicate that slip along \{211\} planes can be constructed of equal segments of slip along alternating $\{110\}$ planes. Accordingly, in the present work we follow the approach of Vitek, Bassani and co-workers by including the nonSchmid stresses in the crystal plasticity formulation for the BCC ferrite and taking the family of $\{110\}$ planes as the only system along which slip potentially operates.

\subsection{Kinematics}

Based on the theory of a large deformations, the total deformation gradient $\boldsymbol{F}$ is decomposed as [21-23]

$$
\boldsymbol{F}=\boldsymbol{F}_{\mathrm{e}} \boldsymbol{F}_{\mathrm{p}},
$$

where $\boldsymbol{F}_{\mathrm{e}}$ describes the elastic distortion of the lattice and $\boldsymbol{F}_{\mathrm{p}}$ represents the deformation related to cumulative plastic slips. It is assumed that the plastic deformation gradient $\boldsymbol{F}_{\mathrm{p}}$ does not change the lattice structure and that the elastic material properties remain unaltered during a deformation process. As shown in figure 1, the decomposition of the total deformation gradient $\boldsymbol{F}$ can be schematized through the introduction of an undeformed reference configuration, a stress-free intermediate configuration and a current configuration. The velocity gradient in the current configuration, $\hat{\boldsymbol{L}}$, can be written as the sum of the elastic part $\hat{\boldsymbol{L}}_{\mathrm{e}}$ and the plastic part $\hat{\boldsymbol{L}}_{\mathrm{p}}$, i.e.

$$
\hat{\boldsymbol{L}}=\dot{\boldsymbol{F}} \boldsymbol{F}^{-1}=\dot{\boldsymbol{F}}_{\mathrm{e}} \boldsymbol{F}_{\mathrm{e}}^{-1}+\boldsymbol{F}_{\mathrm{e}} \dot{\boldsymbol{F}}_{\mathrm{p}} \boldsymbol{F}_{\mathrm{p}}^{-1} \boldsymbol{F}_{\mathrm{e}}^{-1}:=\hat{\boldsymbol{L}}_{\mathrm{e}}+\hat{\boldsymbol{L}}_{\mathrm{p}},
$$

where equation (1) has been invoked to construct the material time derivative of the deformation gradient $\dot{\boldsymbol{F}}$. The plastic part of the velocity gradient $\hat{\boldsymbol{L}}_{\mathrm{p}}$ is determined by the cumulative slip 
rates on all possible slip systems $i$ as

$$
\hat{\boldsymbol{L}}_{\mathrm{p}}:=\boldsymbol{F}_{\mathrm{e}} \dot{\boldsymbol{F}}_{\mathrm{p}} \boldsymbol{F}_{\mathrm{p}}^{-1} \boldsymbol{F}_{\mathrm{e}}^{-1}=\sum_{i=1}^{N} \dot{\gamma}^{(i)} \hat{\boldsymbol{m}}^{(i)} \otimes \hat{\boldsymbol{n}}^{(i)},
$$

where $\dot{\gamma}^{(i)}$ is the slip rate, $\hat{\boldsymbol{m}}^{(i)}$ and $\hat{\boldsymbol{n}}^{(i)}$ are the slip direction and the normal to the slip plane in the current configuration (also see figure 1) and $N$ is the total number of slip systems. In the intermediate configuration (and also in the reference configuration), we define the slip direction and the normal to the slip plane for a slip system $i$ as $\boldsymbol{m}^{(i)}$ and $\boldsymbol{n}^{(i)}$, respectively. The relations between $\boldsymbol{m}^{(i)}$ and $\hat{\boldsymbol{m}}^{(i)}$ and between $\boldsymbol{n}^{(i)}$ and $\hat{\boldsymbol{n}}^{(i)}$ are given by

$$
\begin{aligned}
& \boldsymbol{m}^{(i)}=\boldsymbol{F}_{\mathrm{e}}^{-1} \hat{\boldsymbol{m}}^{(i)}, \\
& \boldsymbol{n}^{(i)}=\boldsymbol{F}_{\mathrm{e}}^{\mathrm{T}} \hat{\boldsymbol{n}}^{(i)},
\end{aligned}
$$

with the superscript $\mathrm{T}$ indicating the transpose. In BCC crystals, plastic slip is assumed to occur by simple shear; hence $\boldsymbol{m}^{(i)}$ and $\boldsymbol{n}^{(i)}$ are perpendicular to each other. From equations (3)-(5), the plastic velocity gradient in the intermediate configuration $\boldsymbol{L}_{\mathrm{p}}$ can be derived as [24]

$$
\boldsymbol{L}_{\mathrm{p}}:=\dot{\boldsymbol{F}}_{\mathrm{p}} \boldsymbol{F}_{\mathrm{p}}^{-1}=\sum_{i=1}^{N} \dot{\gamma}^{(i)} \boldsymbol{m}^{(i)} \otimes \boldsymbol{n}^{(i)} .
$$

Note that in view of (6) and since $\boldsymbol{m}^{(i)} \cdot \boldsymbol{n}^{(i)}=0, \mathrm{~d}\left(\operatorname{det} \boldsymbol{F}_{\mathrm{p}}\right) / \mathrm{d} t=0$; hence the plastic deformation is isochoric, i.e. $\operatorname{det} \boldsymbol{F}_{\mathrm{p}}(t)=1 \forall t$ if $\operatorname{det} \boldsymbol{F}_{\mathrm{p}}(0)=1$.

\subsection{Schmid stress and constitutive formulation}

The stress power per unit volume in the reference configuration is given by $\boldsymbol{P} \cdot \dot{\boldsymbol{F}}$, where $\boldsymbol{P}$ is the first Piola-Kirchhoff stress in the reference configuration and $\dot{\boldsymbol{F}}$ is the material time derivative of the total deformation gradient. Combining the time derivative of decomposition (1) and the flow rule (6) leads to

$$
\boldsymbol{P} \cdot \dot{\boldsymbol{F}}=\left(\boldsymbol{P F}_{\mathrm{p}}^{\mathrm{T}}\right) \cdot \dot{\boldsymbol{F}}_{\mathrm{e}}+\sum_{i=1}^{N} \tau^{(i)} \dot{\gamma}^{(i)},
$$

with the resolved shear stress (or Schmid stress) $\tau^{(i)}$ of slip system $i$ given by

$$
\tau^{(i)}=\left(\boldsymbol{F}_{\mathrm{e}}^{\mathrm{T}} \boldsymbol{P} \boldsymbol{F}_{\mathrm{p}}^{\mathrm{T}}\right) \cdot\left(\boldsymbol{m}^{(i)} \otimes \boldsymbol{n}^{(i)}\right) .
$$

The term $\boldsymbol{P F} \boldsymbol{F}_{\mathrm{p}}^{\mathrm{T}}$ appearing in (7) is the first Piola-Kirchhoff stress in the intermediate configuration, which is energetically conjugated to the elastic deformation gradient $\boldsymbol{F}_{\mathrm{e}}$. The constitutive relation of the model is formulated in the intermediate configuration, in accordance with

$$
\boldsymbol{S}=\mathbb{C}^{F} \boldsymbol{E}_{\mathrm{e}}
$$

where $\boldsymbol{S}$ is the second Piola-Kirchhoff stress in the intermediate configuration, $\mathbb{C}^{F}$ is a fourthorder elasticity tensor and $\boldsymbol{E}_{\mathrm{e}}$ is the elastic Green-Lagrange strain, given by

$$
\boldsymbol{E}_{\mathrm{e}}=\frac{1}{2}\left(\boldsymbol{F}_{\mathrm{e}}^{\mathrm{T}} \boldsymbol{F}_{\mathrm{e}}-\boldsymbol{I}\right)
$$

with $\boldsymbol{I}$ the second-order identity tensor. The fourth-order elasticity tensor $\mathbb{C}^{F}$ in (9) contains the stiffness components of the BCC ferrite, which, in a commonly used $6 \times 6$ matrix form, 
read

$$
\left[\mathbb{C}^{\mathrm{F}}\right]_{\mathrm{F}}=\left[\begin{array}{cccccc}
\kappa_{1}^{\mathrm{F}} & \kappa_{2}^{\mathrm{F}} & \kappa_{2}^{\mathrm{F}} & & & \\
\kappa_{2}^{\mathrm{F}} & \kappa_{1}^{\mathrm{F}} & \kappa_{2}^{\mathrm{F}} & & & \\
\kappa_{2}^{\mathrm{F}} & \kappa_{2}^{\mathrm{F}} & \kappa_{1}^{\mathrm{F}} & & & \\
& & & \kappa_{3}^{\mathrm{F}} & & \\
& & & & \kappa_{3}^{\mathrm{F}} & \\
& & & & & \kappa_{3}^{\mathrm{F}}
\end{array}\right]_{\mathrm{F}},
$$

where $\kappa_{1}^{\mathrm{F}}=\left(\mathbb{C}_{1111}^{\mathrm{F}}\right)_{\mathrm{F}}=\left(\mathbb{C}_{2222}^{\mathrm{F}}\right)_{\mathrm{F}}=\left(\mathbb{C}_{3333}^{\mathrm{F}}\right)_{\mathrm{F}}, \kappa_{2}^{\mathrm{F}}=\left(\mathbb{C}_{1122}^{\mathrm{F}}\right)_{\mathrm{F}}=\left(\mathbb{C}_{1133}^{\mathrm{F}}\right)_{\mathrm{F}}=\left(\mathbb{C}_{2233}^{\mathrm{F}}\right)_{\mathrm{F}}$, and $\kappa_{3}^{\mathrm{F}}=\left(\mathbb{C}_{1212}^{\mathrm{F}}\right)_{\mathrm{F}}=\left(\mathbb{C}_{1313}^{\mathrm{F}}\right)_{\mathrm{F}}=\left(\mathbb{C}_{2323}^{\mathrm{F}}\right)_{\mathrm{F}}$. In the above representation, the subindex $\mathrm{F}$ indicates that the stiffness components of $\mathbb{C}^{\mathrm{F}}$ are referred to the BCC ferrite lattice basis.

The second Piola-Kirchhoff stress tensor in the intermediate configuration $S$, which appears in (9), is related to the first Piola-Kirchhoff stress in the reference configuration $\boldsymbol{P}$ via

$$
\boldsymbol{S}=\boldsymbol{F}_{\mathrm{e}}^{-1} \boldsymbol{P} \boldsymbol{F}_{\mathrm{p}}^{\mathrm{T}}
$$

where it has been implicitly assumed that $\operatorname{det} \boldsymbol{F}_{\mathrm{p}}=1$. Combining equations (12) and (8) turns the expression for the Schmid stress into

$$
\tau^{(i)}=\left(\boldsymbol{F}_{\mathrm{e}}^{\mathrm{T}} \boldsymbol{F}_{\mathrm{e}} \boldsymbol{S}\right) \cdot\left(\boldsymbol{m}^{(i)} \otimes \boldsymbol{n}^{(i)}\right) .
$$

\subsection{Kinetic relation}

The evolution of the plastic slip is described by a rate-dependent kinetic relation. The specific form for the kinetic relation follows a power law [25,26]:

$$
\dot{\gamma}^{(i)}= \begin{cases}\dot{\gamma}_{0}\left[\left(\frac{\tau^{(i)}}{\tau_{\mathrm{cr}}^{(i)}}\right)^{1 / m}-1\right] & \text { if } \tau^{(i)} \geqslant \tau_{\mathrm{cr}}^{(i)}, \\ 0 & \text { otherwise }\end{cases}
$$

where $\dot{\gamma}_{0}$ is the reference slip rate and $m$ is a parameter that sets the rate-sensitivity of the model. Note that in (14) $\dot{\gamma}^{(i)}$ is always positive, which means that in (6) the positive and negative senses of slip are accounted for separately. Equation (14) illustrates that plastic slip occurs if the Schmid stress $\tau^{(i)}$ on a specific slip system $i$ exceeds the critical resolved shear stress $\tau_{\mathrm{cr}}^{(i)}$. In accordance with the model of Vitek et al [27] for BCC crystals, the criticalresolved shear stress is composed of the slip resistance $s^{(i)}$ and the non-Schmid stress $\tau_{*}^{(i)}$,

$$
\tau_{\mathrm{cr}}^{(i)}=s^{(i)}-a_{*}^{(i)} \tau_{*}^{(i)},
$$

where the non-Schmid stress $\tau_{*}^{(i)}$ is given by

$$
\tau_{*}^{(i)}=\left(\boldsymbol{F}_{\mathrm{e}}^{\mathrm{T}} \boldsymbol{F}_{\mathrm{e}} \boldsymbol{S}\right) \cdot\left(\boldsymbol{m}^{(i)} \otimes \boldsymbol{n}_{*}^{(i)}\right) .
$$

The non-Schmid stress is represented by the shear stress parallel to the slip direction $\boldsymbol{m}^{(i)}$, but acting upon a different plane of the $\{110\}$ family called the non-glide plane. For each slip system, the choice of the corresponding non-glide plane follows from the results of the atomistic simulations presented in Bassani et al [17]. The normal to the non-glide plane is indicated by $\boldsymbol{n}_{*}^{(i)}$. For simplicity, the contributions of non-Schmid stresses acting perpendicular to the slip direction $\boldsymbol{m}^{(i)}$ are not accounted for in the present study. The parameter $a_{*}^{(i)}$ determines the net contribution of the non-Schmid stress $\tau_{*}^{(i)}$ to the critical-resolved shear stress. Note the similarity between the expression for the non-Schmid stress (equation (16)) and the expression for the Schmid stress (equation (13)). As the above model shows, the non-Schmid stress effect can be straightforwardly incorporated in the evolution of plastic slip by substituting equation (15) into (14). 


\subsection{Evolution of slip resistance (hardening law)}

The hardening law used in the crystal plasticity formulation is that proposed by Peirce et al [28]. In this model the evolution of the slip resistance $s^{(i)}$ of an individual slip system $i$ is governed by the following equation:

$$
\dot{s}^{(i)}=\sum_{j=1}^{N} H^{(i, j)} \dot{\gamma}^{(j)},
$$

where $H^{(i, j)}$ is the hardening matrix, which includes the self-hardening and cross-hardening moduli. The components of the hardening matrix $H^{(i, j)}$ in (17) can be concisely written as

$$
H^{(i, j)}=\left[q+(1-q) \delta^{(i, j)}\right] h^{(j)},
$$

with $q$ the latent hardening ratio, which reflects the ratio between cross-hardening and selfhardening, $h^{(j)}$ the self-hardening rate (or single-slip hardening rate) of slip system $j$ and $\delta^{(i, j)}$ the Kronecker delta symbol, given by

$$
\delta^{(i, j)}= \begin{cases}1 & \text { if } i=j, \\ 0 & \text { if } i \neq j\end{cases}
$$

For simplicity, the initial value of the slip resistance $s^{(i)}$ is taken equal for all slip systems, i.e. $s^{(i)}=s_{0}$ when $\gamma^{(i)}=0$. The single-slip hardening parameter $h^{(j)}$ in (18) is computed by adopting the model of Brown et al [29],

$$
h^{(j)}=h_{0}\left(1-\frac{s^{(j)}}{s_{\infty}}\right)^{w},
$$

where $h_{0}, s_{\infty}$ and $w$ are the initial single-slip hardening, the hardening saturation value and the hardening-rate exponent, respectively.

\section{Martensitic transformation model for FCC austenite}

The martensitic transformation of austenitic grains is simulated using the transformation model of Turteltaub and Suiker $[1,2]$. In this model, microstructural information is accounted for at the grain level through combining the crystallographic theory of martensitic transformations $[14,15]$ with averaging techniques of the Voigt type. Accordingly, the transformation model includes (i) the crystallographic information from the lattice scale and the influence of volumetric changes during a transformation, (ii) the orientation effect of the 24 possible martensitic transformation systems with respect to the local stress field, (iii) the influence of carbon concentration on the lattice geometries of austenite and martensite and (iv) the effect of stiffness difference between austenite and martensite on the transformation evolution. The main ingredients of the transformation model of Turteltaub and Suiker [1,2] are summarized in the section below.

\subsection{Kinematics}

Similar to the multiplicative decomposition (1), the total deformation gradient $\boldsymbol{F}$ in the austenitic grain can be decomposed into an elastic deformation gradient $\boldsymbol{F}_{\mathrm{e}}$ and a transformation deformation gradient $\boldsymbol{F}_{\text {tr }}$,

$$
\boldsymbol{F}=\boldsymbol{F}_{\mathrm{e}} \boldsymbol{F}_{\mathrm{tr}} .
$$


As demonstrated by Turteltaub and Suiker [1], an expression for the transformation deformation gradient $\boldsymbol{F}_{\text {tr }}$ can be obtained through applying averaging techniques with respect to the transformation deformation gradients of individual transformation systems $\alpha$, leading to

$$
\boldsymbol{F}_{\mathrm{tr}}=\boldsymbol{I}+\sum_{\alpha=1}^{M} \xi^{(\alpha)} \boldsymbol{b}^{(\alpha)} \otimes \boldsymbol{d}^{(\alpha)},
$$

where $\xi^{(\alpha)}, \boldsymbol{b}^{(\alpha)}$ and $\boldsymbol{d}^{(\alpha)}$ are the martensitic volume fraction, the shape strain vector and the unit vector normal to the habit plane of a specific transformation system $\alpha$, respectively, $\boldsymbol{I}$ is the second-order identity tensor and $M$ represents the total number of transformation systems. The shape strain vector $\boldsymbol{b}^{(\alpha)}$ and the habit plane orientation $\boldsymbol{d}^{(\alpha)}$ are calculated from the crystallographic theory of martensitic transformations [14,15]. For a transformation from FCC austenite to BCT martensite, the total number of transformation systems $M$ is equal to 24 (see, e.g. [30]).

From a modelling point of view, martensitic transformation systems require a similar treatment as slip systems in a crystal plasticity model [12]. However, in contrast to the plastic slips $\gamma^{(i)}$, the martensitic volume fractions $\xi^{(\alpha)}$ are bounded by the following constraints:

$$
\begin{aligned}
& 0 \leqslant \xi^{(\alpha)} \leqslant 1, \quad \alpha=1, \ldots, M, \\
& 0 \leqslant \sum_{\alpha=1}^{M} \xi^{(\alpha)} \leqslant 1 .
\end{aligned}
$$

The volume fraction of the untransformed RA $\xi^{(0)}$ can be computed as

$$
\xi^{(0)}=1-\sum_{\alpha=1}^{M} \xi^{(\alpha)},
$$

and in view of (23) and (25), $0 \leqslant \xi^{(0)} \leqslant 1$.

\subsection{Resolved stress for transformation and constitutive formulation}

An expression for the stress power $\boldsymbol{P} \cdot \dot{\boldsymbol{F}}$ can be obtained by invoking the time derivatives of (21) and (22), which leads to

$$
\boldsymbol{P} \cdot \dot{\boldsymbol{F}}=\left(\boldsymbol{P} \boldsymbol{F}_{\mathrm{tr}}^{T}\right) \cdot \dot{\boldsymbol{F}}_{\mathrm{e}}+\sum_{\alpha=1}^{M} \tau_{m}^{(\alpha)} \dot{\xi}^{(\alpha)},
$$

where $\dot{\xi}^{(\alpha)}$ is the rate of change in the martensitic volume fraction of transformation system $\alpha$ and $\tau_{m}^{(\alpha)}$ is the corresponding resolved stress for transformation, given by

$$
\tau_{m}^{(\alpha)}=\left(\boldsymbol{F}_{\mathrm{e}}^{\mathrm{T}} \boldsymbol{P}\right) \cdot\left(\boldsymbol{b}^{(\alpha)} \otimes \boldsymbol{d}^{(\alpha)}\right) .
$$

The constitutive relation of the model is formulated in the intermediate configuration in accordance with

$$
\boldsymbol{S}=\mathbb{C} \boldsymbol{E}_{\mathrm{e}},
$$

where $\boldsymbol{S}$ is the second Piola-Kirchhoff stress in the intermediate configuration, defined as

$$
\boldsymbol{S}=J_{\mathrm{tr}}^{-1} \boldsymbol{F}_{\mathrm{e}}^{-1} \boldsymbol{P} \boldsymbol{F}_{\mathrm{tr}}^{\mathrm{T}}
$$

where $J_{\text {tr }}=\operatorname{det} \boldsymbol{F}_{\text {tr }}$ and the elastic Green-Lagrange strain $\boldsymbol{E}_{\mathrm{e}}$ is given by equation (10). The fourth-order elasticity tensor $\mathbb{C}$ of the austenite-martensite composite system has the form [1,2]

$$
\mathbb{C}=J_{\operatorname{tr}}^{-1}\left\{\xi^{(0)} \mathbb{C}^{A}+\left(1+\delta_{\mathrm{T}}\right) \sum_{\alpha=1}^{M} \xi^{(\alpha)} \mathbb{C}^{(\alpha)}\right\},
$$


where $\mathbb{C}^{A}$ and $\mathbb{C}^{(\alpha)}$ are the elastic stiffness tensors for austenite and system $\alpha$ of martensite, respectively, and $\delta_{\mathrm{T}}$ is the volumetric change due to transformation,

$$
\delta_{\mathrm{T}}:=\boldsymbol{b}^{(\alpha)} \cdot \boldsymbol{d}^{(\alpha)}, \quad \forall \alpha=1, \ldots, M .
$$

Since during transformation the volume fractions $\xi^{(0)}$ and $\xi^{(\alpha)}$ evolve, so does the elastic stiffness tensor in (30). The components of the fourth-order elasticity tensor $\mathbb{C}^{A}$ with respect to the austenite lattice basis can be displayed in a $6 \times 6$ matrix as follows:

$$
\left[\mathbb{C}^{\mathrm{A}}\right]_{\mathrm{A}}=\left[\begin{array}{cccccc}
\kappa_{1}^{\mathrm{A}} & \kappa_{2}^{\mathrm{A}} & \kappa_{2}^{\mathrm{A}} & & & \\
\kappa_{2}^{\mathrm{A}} & \kappa_{1}^{\mathrm{A}} & \kappa_{2}^{\mathrm{A}} & & & \\
\kappa_{2}^{\mathrm{A}} & \kappa_{2}^{\mathrm{A}} & \kappa_{1}^{\mathrm{A}} & & & \\
& & & \kappa_{3}^{\mathrm{A}} & & \\
& & & & \kappa_{3}^{\mathrm{A}} & \\
& & & & & \kappa_{3}^{\mathrm{A}}
\end{array}\right]_{\mathrm{A}}
$$

where the elastic moduli of FCC austenite are given by $\kappa_{1}^{\mathrm{A}}:=\left(\mathbb{C}_{1111}^{\mathrm{A}}\right)_{\mathrm{A}}=\left(\mathbb{C}_{2222}^{\mathrm{A}}\right)_{\mathrm{A}}=$ $\left(\mathbb{C}_{3333}^{\mathrm{A}}\right)_{\mathrm{A}}, \kappa_{2}^{\mathrm{A}}:=\left(\mathbb{C}_{1122}^{\mathrm{A}}\right)_{\mathrm{A}}=\left(\mathbb{C}_{1133}^{\mathrm{A}}\right)_{\mathrm{A}}=\left(\mathbb{C}_{2233}^{\mathrm{A}}\right)_{\mathrm{A}}$ and $\kappa_{3}^{\mathrm{A}}:=\left(\mathbb{C}_{1212}^{\mathrm{A}}\right)_{\mathrm{A}}=\left(\mathbb{C}_{1313}^{\mathrm{A}}\right)_{\mathrm{A}}=$ $\left(\mathbb{C}_{2323}^{\mathrm{A}}\right)_{\mathrm{A}}$.

A martensitic transformation system $\alpha$ emerges as a twinned structure of two (out of three) BCT martensite variants $\left(\beta_{i}, \beta_{j}\right)$ with corresponding proportions $\left(\lambda^{(\alpha, i)}, \lambda^{(\alpha, j)}\right)$, where $i, j=\{1,2,3\}$ and $i \neq j$. When assuming that the elastic deformations in the martensitic variants are equal, the effective elastic stiffness tensor $\mathbb{C}^{(\alpha)}$, which appears in (30), can be written as

$$
\mathbb{C}^{(\alpha)}=\lambda^{\left(\alpha, \beta_{1}\right)} \mathbb{E}^{\left(\beta_{1}\right)}+\lambda^{\left(\alpha, \beta_{2}\right)} \mathbb{E}^{\left(\beta_{2}\right)},
$$

with $\mathbb{E}^{\left(\beta_{i}\right)}$ the fourth-order elasticity tensor of BCT martensitic variant $\beta_{i}$ in transformation system $\alpha$. The components of the elasticity tensor $\mathbb{E}^{(3)}$ of martensitic variant 3 can be expressed with respect to its own lattice basis as

$$
\left[\mathbb{E}^{(3)}\right]_{(\alpha, 3)}=\left[\begin{array}{lllllll}
\kappa_{1}^{\mathrm{M}} & \kappa_{2}^{\mathrm{M}} & \kappa_{3}^{\mathrm{M}} & & & \\
\kappa_{2}^{\mathrm{M}} & \kappa_{1}^{\mathrm{M}} & \kappa_{3}^{\mathrm{M}} & & & \\
\kappa_{3}^{\mathrm{M}} & \kappa_{3}^{\mathrm{M}} & \kappa_{4}^{\mathrm{M}} & & & \\
& & & \kappa_{5}^{\mathrm{M}} & & \\
& & & & \kappa_{5}^{\mathrm{M}} & \\
& & & & & \kappa_{6}^{\mathrm{M}}
\end{array}\right]_{(\alpha, 3)}
$$

where the elastic moduli of martensitic variant 3 are $\kappa_{1}^{\mathrm{M}}:=\left(\mathbb{E}_{1111}^{(3)}\right)_{(\alpha, 3)}=\left(\mathbb{E}_{2222}^{(3)}\right)_{(\alpha, 3)}$, $\kappa_{2}^{\mathrm{M}}:=\left(\mathbb{E}_{1122}^{(3)}\right)_{(\alpha, 3)}, \kappa_{3}^{\mathrm{M}}=\left(\mathbb{E}_{1133}^{(3)}\right)_{(\alpha, 3)}=\left(\mathbb{E}_{2233}^{(3)}\right)_{(\alpha, 3)}, \kappa_{4}^{\mathrm{M}}=\left(\mathbb{E}_{3333}^{(3)}\right)_{(\alpha, 3)}, \kappa_{5}^{\mathrm{M}}:=\left(\mathbb{E}_{1313}^{(3)}\right)_{(\alpha, 3)}=$ $\left(\mathbb{E}_{2323}^{(3)}\right)_{(\alpha, 3)}$ and $\kappa_{6}^{\mathrm{M}}:=\left(\mathbb{E}_{1212}^{(3)}\right)_{(\alpha, 3)}$. The components of the stiffness tensors of martensitic variants 1 and 2 can be found from equation (34) by symmetry, as explained in Turteltaub and Suiker [1]. Through rotations that map the BCT martensite lattice bases to the parent FCC austenite lattice basis (which is used as a common basis for all martensitic transformation systems $\alpha=1, \ldots, M)$, the components of the tensor $\mathbb{C}^{(\alpha)}$ in (33) can be expressed relative to the FCC austenite lattice basis. More details about the construction of the elasticity tensor in (33) can be found in Turteltaub and Suiker [1,2] and Suiker and Turteltaub [12].

\subsection{Transformation driving force}

The expression for the driving force for transformation is derived from the procedure of Coleman and Noll [31] that requires a formulation of the energy dissipation and subsequent 
application of the second law of thermodynamics. Through this procedure the rate of change in the martensitic volume fraction $\dot{\xi}^{(\alpha)}$ is identified as a flux and the driving force $f^{(\alpha)}$ as the corresponding affinity. The driving force for transformation has the following form [1]:

$$
\begin{aligned}
f^{(\alpha)}= & J_{\mathrm{tr}}\left(\boldsymbol{F}_{\mathrm{e}}^{\mathrm{T}} \boldsymbol{F}_{\mathrm{e}} \boldsymbol{S} \boldsymbol{F}_{\mathrm{tr}}^{-\mathrm{T}}\right) \cdot\left(\boldsymbol{b}^{(\alpha)} \otimes \boldsymbol{d}^{(\alpha)}\right)+\frac{1}{2}\left[\left(\mathbb{C}^{A}-\left(1+\delta_{\mathrm{T}}\right) \mathbb{C}^{(\alpha)}\right) \boldsymbol{E}_{\mathrm{e}}\right] \cdot \boldsymbol{E}_{\mathrm{e}} \\
& -\frac{\chi}{l_{0}}\left(1-2 \xi^{(\alpha)}\right)+f_{\mathrm{th}}^{(\alpha)}
\end{aligned}
$$

where $\chi$ is the surface energy per unit area of the austenite-twinned martensite interfaces and $l_{0}$ is a length scale parameter reflecting the volume-to-surface ratio of a martensitic platelet. Furthermore, $f_{\text {th }}^{(\alpha)}$ is the thermal contribution to the driving force. For the isothermal boundary value problems considered in this study, the thermal driving force $f_{\text {th }}^{(\alpha)}$ is constant.

\subsection{Kinetic relation}

The evolution of the martensitic volume fraction during transformation is defined through a ratedependent kinetic relation that takes explicitly into account a non-zero transformation barrier. Accordingly, a transformation system $\alpha$ becomes active when the corresponding driving force $f^{(\alpha)}$ exceeds the critical driving force $f_{\mathrm{cr}}^{(\alpha)}$. In the present study, the rate-dependent kinetic relation proposed by Turteltaub and Suiker $[1,2]$ is adopted, i.e.

$$
\dot{\xi}^{(\alpha)}= \begin{cases}\dot{\xi}_{\max }^{(\alpha)} \tanh \left(\frac{1}{v^{(\alpha)}} \frac{f^{(\alpha)}-f_{\mathrm{cr}}^{(\alpha)}}{f_{\mathrm{cr}}^{(\alpha)}}\right) & \text { if } f^{(\alpha)} \geqslant f_{\mathrm{cr}}^{(\alpha)}, \\ 0 & \text { otherwise, }\end{cases}
$$

where $\dot{\xi}_{\max }^{(\alpha)}$ is the maximum transformation rate and $v^{(\alpha)}$ is a viscosity-like parameter. For simplicity, the values of $f_{\mathrm{cr}}^{(\alpha)}, \dot{\xi}_{\max }^{(\alpha)}$ and $\nu^{(\alpha)}$ are assumed to be constant and are taken equal for all transformation systems, i.e. $f_{\mathrm{cr}}^{(\alpha)}=f_{\mathrm{cr}}, \dot{\xi}_{\max }^{(\alpha)}=\dot{\xi}_{\max }$ and $v^{(\alpha)}=v$. As shown in Turteltaub and Suiker [1], the rate-dependent kinetic relation in (36) satisfies the second law of thermodynamics and reduces to the rate-independent transformation criterion $f^{(\alpha)}=f_{\mathrm{cr}}^{(\alpha)}$ when $v^{(\alpha)} \rightarrow 0, \dot{\xi}_{\max }^{(\alpha)} \rightarrow \infty$ or if the loading rate becomes infinitely high, such that $\dot{\xi}^{(\alpha)} \rightarrow \infty$.

\section{Numerical simulations}

The influence of the austenite and ferrite grain orientations on the effective response of a TRIP steel sample is examined through three-dimensional finite element analyses. For this purpose, the crystal plasticity model and the martensitic transformation model outlined in sections 2 and 3 are implemented as 'user subroutines' in the finite element program ABAQUS [32]. The numerical implementation of the martensitic transformation model follows an integration scheme where the stress update is performed within the framework of finite deformations and is based on a fully implicit backward Euler algorithm [12]. In addition, the consistent tangent operator is computed through a numerical differentiation method, which avoids the analytical evaluation of the relatively complex derivatives that depend on the specific transformation systems activated. The transformation systems activated during deformation are determined through a robust search algorithm, as explained in detail in Suiker and Turteltaub [12]. For the crystal plasticity model, a numerical implementation similar to that proposed by Cuitiño and Ortiz [25] has been adopted, together with improvements taken from the numerical implementation of the phase transformation model [12]. In fact, the numerical implementations of the crystal plasticity model and the phase transformation model show certain similarities that stem from the analogy between slip systems and transformation systems. 


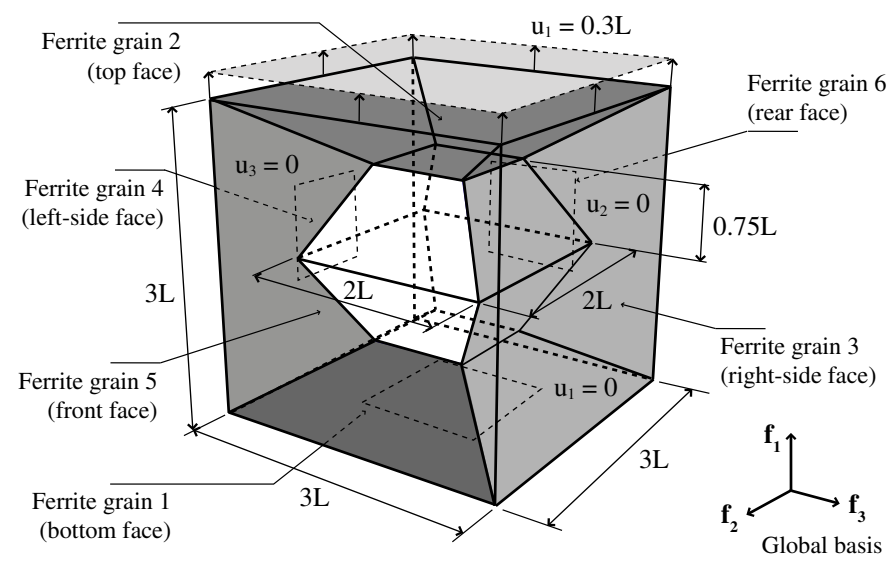

Figure 2. Geometry and boundary conditions of a TRIP steel microstructure consisting of a single grain of RA embedded in a matrix of six ferritic grains.

\subsection{Geometry and boundary conditions}

The TRIP steel sample analysed numerically consist of a $3 L \times 3 L \times 3 L$ cube containing a grain of RA embedded in a ferrite-based matrix (see figure 2). The grain of RA is modelled as a polyhedron composed of two half-pyramids. Each half-pyramid has a $2 L \times 2 L$ rectangular base and a concentric $L \times L$ rectangular top. The height of the half-pyramids is $0.75 L$. Since typical grains of RA have a characteristic length of about $2 \mu \mathrm{m}$ [3], we take $L=1 \mu \mathrm{m}$. The initial volume of the RA grain is approximately equal to $15 \%$ of the overall sample volume. The ferrite-based matrix is divided into six sub-domains, where each sub-domain represents the partial geometry of a single grain of ferrite. The cutting planes of the sub-domains are defined by connecting the external edges of the cube to the corresponding edges of the austenite inclusion. The global basis is defined in terms of unit vectors $\left\{\boldsymbol{f}_{1}, \boldsymbol{f}_{2}, \boldsymbol{f}_{3}\right\}$ (see figure 2).

The material is initially stress-free and subsequently subjected to a uniaxial tensile loading. As illustrated in figure 2, this loading corresponds to the following boundary conditions: (i) the normal displacement and the tangential tractions on the external faces of grains 1, 4 and 6 are set to zero, (ii) the uniaxial tensile loading is applied in the $f_{1}$-direction by imposing a normal displacement $u_{1}=(0.3 L)(t / T)$ and zero tangential tractions on the external face of grain 2 , which, at a nominal straining rate of $10^{-3} \mathrm{~s}^{-1}$, eventually leads to a maximum nominal axial strain of $10 \%$ for a total analysis time $T=100 \mathrm{~s}$ and (iii) the two remaining faces are traction-free. The simulations are carried out at an ambient temperature of $300 \mathrm{~K}$.

In order to study the effects of grain orientation on the overall response of the TRIP steel sample, the orientations of the grains are varied in accordance with the values listed in table 1. All orientations are given in terms of the so-called 323 Euler rotations that map the global basis to a local lattice basis, which is either the lattice basis of the austenite or the lattice basis of the ferrite. For the sake of clarity, certain orientations are also referred to using the Miller indices of the global vector $f_{1}$ in the corresponding lattice basis. More specifically, the orientations $\left(0^{\circ}, 0^{\circ}, 0^{\circ}\right)$ and $\left(45^{\circ}, 35.26^{\circ}, 0^{\circ}\right)$ correspond to the [100] and [111] orientations, respectively, where a subindex $A$ or a subindex $F$ is added to the orientations to designate the reference to the austenite and ferrite lattice bases (see table 1).

Cases 1, 2, 4 and 5 in table 1 represent a RA grain embedded in a single crystal ferritic matrix while cases 3 and 6 reflect a RA grain embedded in a multi-crystal ferritic matrix. The 
Table 1. Selected orientations of the RA grain and ferrite grains, given in terms of 323 Euler angles. The Euler angles are defined with respect to the global basis $\left\{f_{1}, f_{2}, f_{3}\right\}$.

\begin{tabular}{|c|c|c|}
\hline Case & RA grain & Ferrite grains \\
\hline 1 & $\begin{array}{l}f_{1}=[100]_{\mathrm{A}} \text { or } \\
\left(0^{\circ}, 0^{\circ}, 0^{\circ}\right)\end{array}$ & $\begin{array}{l}1,2,3,4,5 \text { and } 6: f_{1}=[100]_{\mathrm{F}} \text { or } \\
\left(0^{\circ}, 0^{\circ}, 0^{\circ}\right)\end{array}$ \\
\hline 2 & $\begin{array}{l}f_{1}=[100]_{\mathrm{A}} \text { or } \\
\left(0^{\circ}, 0^{\circ}, 0^{\circ}\right)\end{array}$ & $\begin{array}{c}1,2,3,4,5 \text { and } 6: f_{1}=[111]_{\mathrm{F}} \text { or } \\
\left(45^{\circ}, 35.26^{\circ}, 0^{\circ}\right)\end{array}$ \\
\hline 3 & $\begin{array}{l}f_{1}=[100]_{\mathrm{A}} \text { or } \\
\left(0^{\circ}, 0^{\circ}, 0^{\circ}\right)\end{array}$ & $\begin{array}{lll}\text { 1: }\left(0^{\circ}, 0^{\circ}, 0^{\circ}\right) & 2:\left(45^{\circ}, 0^{\circ}, 0^{\circ}\right) & 3:\left(45^{\circ}, 35.26^{\circ}, 0^{\circ}\right) \\
4:\left(22.5^{\circ}, 0^{\circ}, 0^{\circ}\right) & 5:\left(22.5^{\circ}, 17.63^{\circ}, 0^{\circ}\right) & 6:\left(45^{\circ}, 17.63^{\circ}, 0^{\circ}\right)\end{array}$ \\
\hline 4 & $\begin{array}{l}f_{1}=[111]_{A} \text { or } \\
\left(45^{\circ}, 35.26^{\circ}, 0^{\circ}\right)\end{array}$ & $\begin{array}{c}1,2,3,4,5 \text { and } 6: f_{1}=[100]_{\mathrm{F}} \text { or } \\
\left(0^{\circ}, 0^{\circ}, 0^{\circ}\right)\end{array}$ \\
\hline 5 & $\begin{array}{l}f_{1}=[111]_{\mathrm{A}} \text { or } \\
\left(45^{\circ}, 35.26^{\circ}, 0^{\circ}\right)\end{array}$ & $\begin{array}{c}1,2,3,4,5 \text { and } 6: f_{1}=[111]_{\mathrm{F}} \text { or } \\
\left(45^{\circ}, 35.26^{\circ}, 0^{\circ}\right)\end{array}$ \\
\hline 6 & $\begin{array}{l}f_{1}=[111]_{\mathrm{A}} \text { or } \\
\left(45^{\circ}, 35.26^{\circ}, 0^{\circ}\right)\end{array}$ & $\begin{array}{ll}2:\left(45^{\circ}, 0^{\circ}, 0^{\circ}\right) & 3:\left(45^{\circ}, 35.26^{\circ}, 0^{\circ}\right) \\
5:\left(22.5^{\circ}, 17.63^{\circ}, 0^{\circ}\right) & 6:\left(45^{\circ}, 17.63^{\circ}, 0^{\circ}\right)\end{array}$ \\
\hline
\end{tabular}

Table 2. Material parameters of the crystal plasticity model for ferrite.

\begin{tabular}{ll}
\hline Elastic moduli & $\kappa_{1}^{\mathrm{F}}=233.5 \mathrm{GPa}, \kappa_{2}^{\mathrm{F}}=135.5 \mathrm{GPa}$ \\
& $\kappa_{3}^{\mathrm{F}}=118 \mathrm{GPa}$ (equation (11)) \\
Non-Schmid stress weight parameter & $a_{*}^{(i)}=a_{*}=0.12$ (equation (15)) \\
Kinetic law & $m=0.01, \dot{\gamma}_{0}=10^{-3} \mathrm{~s}^{-1}$ (equation (14)) \\
Initial slip resistance & $s_{0}=100 \mathrm{MPa}$ \\
Hardening law & $s_{\infty}=400 \mathrm{MPa}, h_{0}=8.2 \mathrm{GPa}, w=2.8$ \\
& $q=1$ (equations (18) and (20)) \\
\hline
\end{tabular}

Euler angles of the grain orientations in the multi-crystalline ferritic matrix are chosen such that they are evenly distributed in the orientation space. Accordingly, the ferritic grains 1, 2 and 3 are given the $[100]_{\mathrm{F}},[110]_{\mathrm{F}}$, and $[111]_{\mathrm{F}}$ orientations, respectively. The Euler angles of ferritic grain 4 are equal to the average values of the Euler angles of ferritic grains 1 and 2, whereas the Euler angles of grains 5 and 6 are equal to the average values of the Euler angles of grains 1 and 3 and grains 2 and 3, respectively.

\subsection{Model parameters}

The parameters used in the crystal plasticity model are summarized in table 2. The elastic moduli for the $\mathrm{BCC}$ ferrite are based on the results of $\mathrm{x}$-ray diffraction measurements reported by Liu et al [33]. For simplicity, it is assumed that the values of the weight parameters $a_{*}^{(i)}$ are the same for all slip systems, i.e. $a_{*}^{(i)}=a_{*}$. The weight parameter $a_{*}$ is calibrated from the data of uniaxial tensile tests on single-crystal ferrite samples obtained by Franciosi [20], which clearly show an orientation dependence of the initial critical resolved shear stress for plastic slip. The calibration procedure applied is taken from Bassani et al [17], which uses the asymmetric responses in the twinning and anti-twinning directions to determine $a_{*}$.

The parameters used for the kinetic law are chosen such that rate effects remain small under quasi-static loading conditions; that is, the response of the rate-dependent model is close to that of a rate-independent crystal plasticity model. The purpose of introducing a small rate-dependence is to avoid numerical singularity problems typically encountered for rateindependent crystal plasticity models [26]. The initial slip resistance $s_{0}$ and the parameters $h_{0}$, $w$ and $q$ used in the hardening law are calibrated from experimental uniaxial stress-strain data of a dual phase poly-crystalline sample consisting mostly of ferrite, as reported by Jacques et al 
Table 3. Slip directions $\boldsymbol{m}^{(i)}$ slip plane normals $\boldsymbol{n}^{(i)}$, and non-glide plane normals $\boldsymbol{n}_{*}^{(i)}$ used in the $\mathrm{BCC}$ ferrite model. The vectors are formulated with respect to the ferrite lattice basis.

\begin{tabular}{llllllll}
\hline$i$ & $\boldsymbol{m}^{(i)}$ & $\boldsymbol{n}^{(i)}$ & $\boldsymbol{n}_{*}^{(i)}$ & $i$ & $\boldsymbol{m}^{(i)}$ & $\boldsymbol{n}^{(i)}$ & $\boldsymbol{n}_{*}^{(i)}$ \\
\hline 1 & {$[111]$} & $(01 \overline{1})$ & $(\overline{1} 10)$ & 2 & {$[\overline{1} \overline{1} \overline{1}]$} & $(01 \overline{1})$ & $(10 \overline{1})$ \\
3 & {$[111]$} & $(\overline{1} 01)$ & $(0 \overline{1} 1)$ & 4 & {$[\overline{1} \overline{1} \overline{1}]$} & $(\overline{1} 01)$ & $(\overline{1} 10)$ \\
5 & {$[111]$} & $(1 \overline{1} 0)$ & $(10 \overline{1})$ & 6 & {$[\overline{1} \overline{1} \overline{1}]$} & $(1 \overline{1} 0)$ & $(0 \overline{1} 1)$ \\
7 & {$[\overline{1} 11]$} & $(0 \overline{1} 1)$ & $(101)$ & 8 & {$[1 \overline{1} \overline{1}]$} & $(0 \overline{1} 1)$ & $(\overline{1} \overline{1} 0)$ \\
9 & {$[\overline{1} 11]$} & $(\overline{1} 0 \overline{1})$ & $(\overline{1} \overline{1} 0)$ & 10 & {$[1 \overline{1} \overline{1}]$} & $(\overline{1} 0 \overline{1})$ & $(01 \overline{1})$ \\
11 & {$[\overline{1} 11]$} & $(110)$ & $(01 \overline{1})$ & 12 & {$[1 \overline{1} \overline{1} \overline{1}$} & $(110)$ & $(101)$ \\
13 & {$[\overline{1} \overline{1} 1]$} & $(101)$ & $(011)$ & 14 & {$[11 \overline{1}]$} & $(101)$ & $(1 \overline{1} 0)$ \\
15 & {$[\overline{1} \overline{1} 1]$} & $(0 \overline{1} \overline{1})$ & $(1 \overline{1} 0)$ & 16 & {$[11 \overline{1}]$} & $(0 \overline{1} \overline{1})$ & $(\overline{1} 0 \overline{1})$ \\
17 & {$[\overline{1} \overline{1} 1]$} & $(\overline{1} 10)$ & $(\overline{1} 0 \overline{1})$ & 18 & {$[11 \overline{1}]$} & $(\overline{1} 10)$ & $(01 \overline{1})$ \\
19 & {$[1 \overline{1} 1]$} & $(10 \overline{1})$ & $(110)$ & 20 & {$[\overline{1} 1 \overline{1}]$} & $(10 \overline{1})$ & $(0 \overline{1} \overline{1})$ \\
21 & {$[1 \overline{1} 1]$} & $(011)$ & $(\overline{1} 01)$ & 22 & {$[\overline{1} \overline{1} \overline{1}]$} & $(011)$ & $(110)$ \\
23 & {$[1 \overline{1} 1]$} & $(\overline{1} \overline{1} 0)$ & $(0 \overline{1} \overline{1})$ & 24 & {$[\overline{1} 1 \overline{1} \overline{1}]$} & $(\overline{1} \overline{1} 0)$ & $(\overline{1} 01)$ \\
\hline
\end{tabular}

Table 4. Material parameters for the martensitic transformation model.

\begin{tabular}{ll}
\hline Austenite elastic moduli & $\kappa_{1}^{\mathrm{A}}=268.5 \mathrm{GPa}, \kappa_{2}^{\mathrm{A}}=156 \mathrm{GPa}$ \\
& $\kappa_{3}^{\mathrm{A}}=136 \mathrm{GPa}($ equation (32)) \\
Martensite elastic moduli & $\kappa_{1}^{\mathrm{M}}=497 \mathrm{GPa}, \kappa_{2}^{\mathrm{M}}=405 \mathrm{GPa}$ \\
& $\kappa_{3}^{\mathrm{M}}=265 \mathrm{GPa}, \kappa_{4}^{\mathrm{M}}=617 \mathrm{GPa}$ \\
& $\kappa_{5}^{\mathrm{M}}=263 \mathrm{GPa}, \kappa_{6}^{\mathrm{M}}=287 \mathrm{GPa}$ (equation (34)) \\
Transformation volume dilatation & $\delta_{\mathrm{T}}=0.0391($ equation $(30))$ \\
Kinetic law & $v=0.17, \dot{\xi}_{\mathrm{max}}=3 \times 10^{-3} \mathrm{~s}^{-1}$ (equation (36)) \\
Critical transformation value & $f_{\mathrm{cr}}-f_{\text {th }}=5 \mathrm{MPa}($ equation (35)) \\
Surface energy & $\chi=0.2 \mathrm{~J} \cdot \mathrm{m}^{-2}, l_{0}=0.05 \mu \mathrm{m}$ (equation (35)) \\
\hline
\end{tabular}

[3]. In the calibration procedure, the poly-crystalline response is simulated by combining the present crystal plasticity model with a Taylor averaging procedure [34]. The slip directions, the normal vectors of the slip planes and the normal vectors of the non-glide planes used in the BCC crystal plasticity model are listed in table 3.

The parameters for the martensitic transformation model are presented in table 4 . The values in this table are representative of an austenite grain with a carbon concentration of $1.4 \mathrm{wt} . \%$, for which the transformation product phase at room temperature is typically a twinned, thin-plate martensite $[35,36]$. Similarly to the kinetic law of the crystal plasticity model, the parameters for the kinetic law of the transformation model are chosen to reflect a 'weak' rate-dependent transformation behaviour under quasi-static loading conditions. The effective critical transformation value, which, under isothermal conditions, may be represented by the difference between the transformation threshold $f_{\text {cr }}$ and the (constant) thermal contribution to the driving force $f_{\text {th }}$, is taken as $5 \mathrm{MPa}$. The details of the calibration procedure that leads to the parameter set in table 4 can be found in Turteltaub and Suiker [2].

\subsection{Simulation results}

For the graphical representation of the simulation results, we define the volume average of the normal Cauchy stress $\bar{T}_{11}$ in the loading direction as

$$
\bar{T}_{11}(t):=\frac{1}{\left|\Omega_{t}\right|} \int_{\Omega_{t}} T_{11}(z, t) \mathrm{d} v_{z},
$$


where $T_{11}$ is the normal Cauchy stress in the loading direction (which is $f_{1}$ ), $\Omega_{t}$ is the computational domain in the current configuration at time $t$ and $z$ is the position of a material point in the current configuration (see figure 1). The strain measure used in the presentation of the results is the logarithmic strain $\boldsymbol{e}$, which is defined as

$$
e:=\ln V \text {, }
$$

with $\boldsymbol{V}$ is the left stretch tensor obtained from a polar decomposition of the deformation gradient $\boldsymbol{F}$, i.e. $\boldsymbol{F}=\boldsymbol{V} \boldsymbol{Q}$, where $\boldsymbol{Q}$ is the rigid body rotation. The average logarithmic strain in the loading direction is computed as

$$
\bar{e}_{11}(t):=\frac{1}{\left|\Omega_{0}\right|} \int_{\Omega_{0}} e_{11}(\boldsymbol{x}, t) \mathrm{d} v_{x},
$$

where $e_{11}$ is the normal logarithmic strain in the loading direction and $\Omega_{0}$ is the computational domain in the reference configuration.

4.3.1. Influence of the RA orientation on the effective strength. In figure 3 the effective stress-strain responses to uniaxial loading are plotted for various samples composed of an austenitic grain embedded in a single-crystal ferritic matrix. In correspondence with table 1, the orientations of the single-crystal ferrite are $[100]_{\mathrm{F}}$ (figure $3(a)$ ) and $[111]_{\mathrm{F}}$ (figure $3(b)$ ). For comparison, both figures also contain the response of a cubic sample with the austenitic grain being replaced by a ferritic grain with the same orientation as the surrounding ferritic grains, indicated as 'ferrite matrix only'. It can be noted that samples with an austenitic grain oriented in the $[100]_{\mathrm{A}}$ direction (cases 1 and 2) initially have a lower effective strength than the 'ferrite matrix only'. Accordingly, these samples may be characterized as 'weak'. The low effective strength of a sample with a $[100]_{\mathrm{A}}$-oriented grain is due to the capability of the austenitic grain to accommodate the externally imposed deformation without a significant increase in stress. This behaviour was also observed in the analyses reported by Turteltaub and Suiker [1,2], which showed that a $[100]_{\mathrm{A}}$-oriented austenitic grain subjected to homogeneous uniaxial loading conditions transforms at a relatively low stress value that remains virtually constant during the transformation process (i.e. a stress plateau). Nonetheless, at the end of the transformation process the stress typically increases, as can be seen in figures $3(a)$ and (b). This increase in stress may be ascribed to two factors, namely (i) the exhaustion of the available stress-free transformation strain to accommodate the imposed deformation and (ii) the increase in stiffness due to a martensite-rich microstructure. The increase in stiffness is related to the increase in hardness upon transformation of RA to martensite.

Figures $3(a)$ and $(b)$ further show that the effective strength of a sample with a $[111]_{\mathrm{A}^{-}}$ oriented austenitic grain (cases 4 and 5) is higher than the effective strength of a corresponding sample with a $[100]_{\mathrm{A}}$-oriented austenitic grain (cases 1 and 2). The stronger behaviour of the samples with a $[111]_{\mathrm{A}}$-oriented austenitic grain can be ascribed to the fact that the transformation into martensite requires a higher stress at the grain level. Since a higher transformation stress is typically associated with a lower transformation strain $[1,2]$, the samples with a $[111]_{\mathrm{A}}$-oriented austenitic grain need less deformation to overcome the transformation than the samples with a $[100]_{A}$-oriented austenitic grain. In figures $3(a)$ and (b) this is indicated by the fact that the stress increase at the end of the transformation process for a sample with a $[111]_{\mathrm{A}}$-oriented austenitic grain occurs at a lower uniaxial strain than for a corresponding sample with a $[100]_{\mathrm{A}}$-oriented austenitic grain. In general, the variation in the overall responses of the samples due to differences in the austenite orientation is significant, especially by considering the fact that the RA occupies only $15 \%$ of the total volume.

Comparing figures $3(a)$ and $(b)$ illustrates that the single-crystal ferrite oriented in the $[111]_{\mathrm{F}}$ direction provides a higher sample strength than the ferrite oriented in the $[100]_{\mathrm{F}}$ 

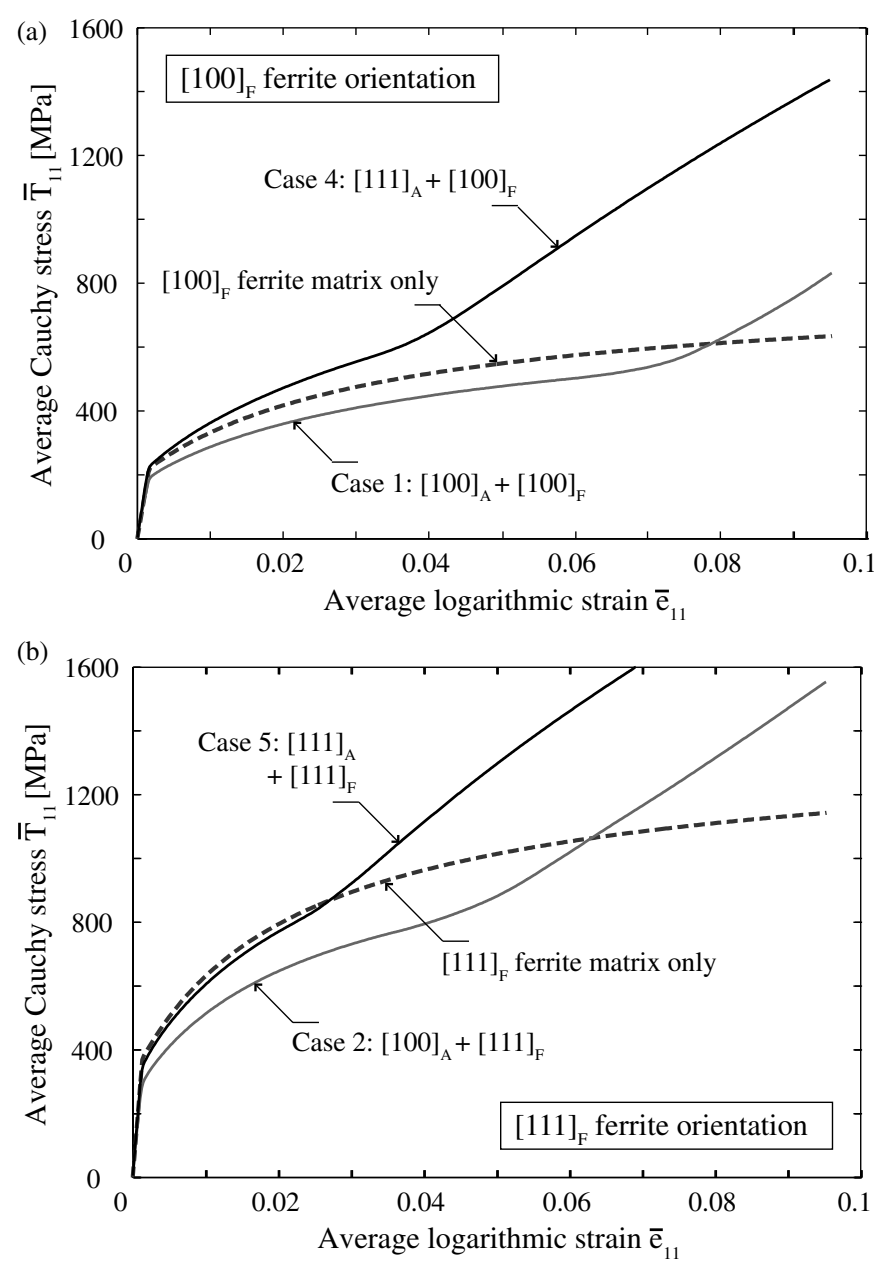

Figure 3. Average Cauchy stress $\bar{T}_{11}$ versus average logarithmic strain $\bar{e}_{11}$. The austenite orientation in the samples is varied while the ferrite orientation is kept constant, i.e. $[100]_{\mathrm{F}}$ in (a) and $[111]_{\mathrm{F}}$ in $(b)$.

direction. In fact, the stress required for initiating plastic slip in $[111]_{\mathrm{F}}$-oriented grains is even higher than the stress required for initiating transformation in $[111]_{\mathrm{A}}$-oriented grains, as a result of which the overall strength of the $[111]_{\mathrm{A}}-[111]_{\mathrm{F}}$ sample (case 5) is initially lower than the effective strength of the $[111]_{\mathrm{F}}$ 'ferrite matrix only' (see figure $3(b)$ ). Nevertheless, after the formation of a substantial amount of martensite the $[111]_{\mathrm{A}}-[111]_{\mathrm{F}}$ sample provides the highest effective strength for all microstructures analysed.

4.3.2. Influence of the ferrite orientation on the effective strength. In figure 4 the effective stress-strain responses of various samples are depicted for a fixed orientation of the RA grain, which is $[100]_{\mathrm{A}}$ in figure $4(a)$ and $[111]_{\mathrm{A}}$ in $(b)$. The matrix composed of anisotropic ferritic grains is either single-crystalline (cases 1,2,4 and 5) or multi-crystalline (cases 3 and 6). For comparison, the responses for an isotropic ferritic matrix are also depicted, as obtained by using an isotropic elasto-plasticity model for the ferritic matrix. The results of the latter 

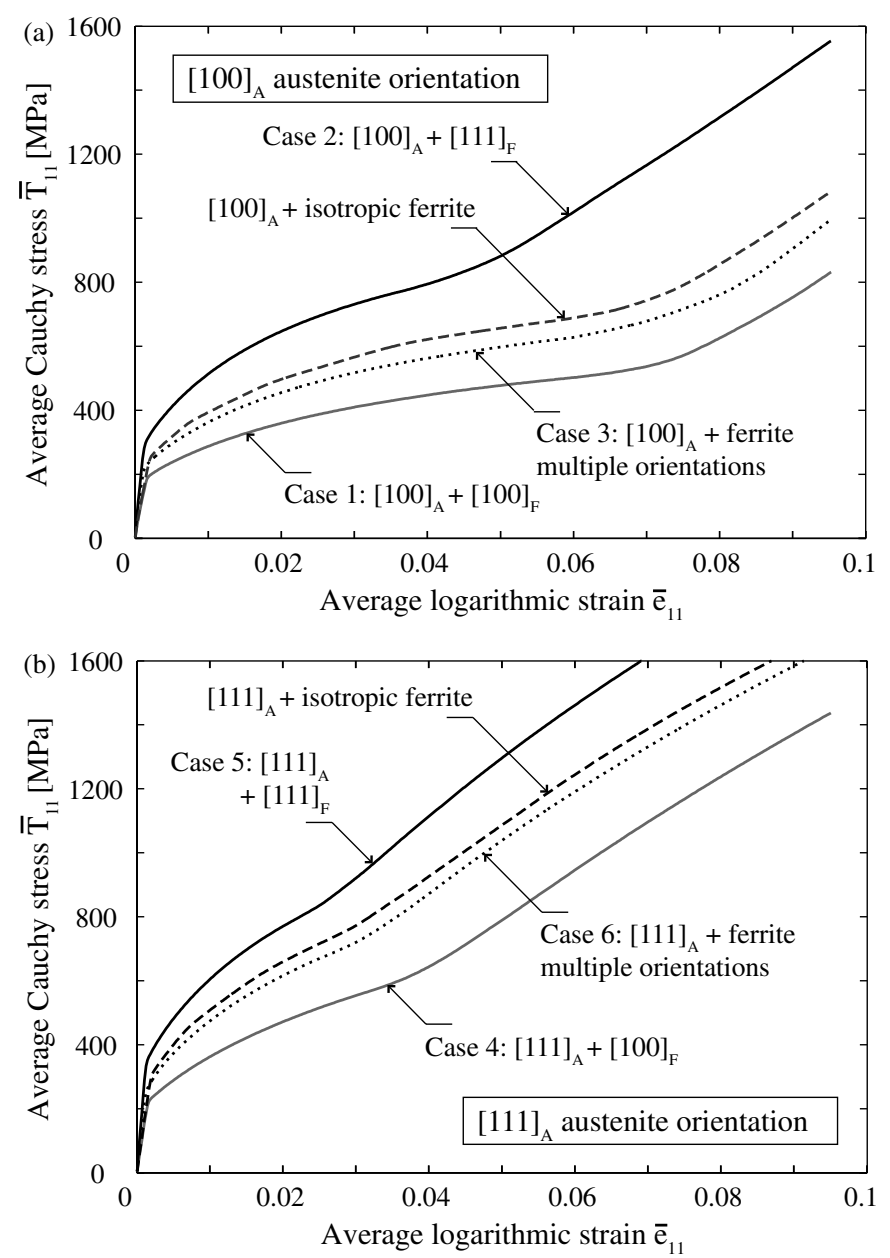

Figure 4. Average Cauchy stress $\bar{T}_{11}$ versus average logarithmic strain $\bar{e}_{11}$. The ferrite orientation in the samples is varied while the austenite orientation is kept constant, i.e. $[100]_{\mathrm{A}}$ in $(a)$ and $[111]_{\mathrm{A}}$ in $(b)$.

simulations were presented previously in Turteltaub and Suiker [2]. In correspondence with the results in figure 3 , a single-crystalline matrix of [111 $]_{\mathrm{F}}$-oriented ferritic grains (cases 2 and 5 in figures $4(a)$ and $(b)$, respectively) provides a relatively high effective strength. Conversely, samples with a single-crystalline matrix of $[100]_{\mathrm{F}}$-oriented ferritic grains (cases 1 and 4 in figures $4(a)$ and $(b)$, respectively) relate to a low effective strength. Note that the $[111]_{\mathrm{A}}-[111]_{\mathrm{F}}$ sample and the $[100]_{\mathrm{A}}-[100]_{\mathrm{F}}$ sample, respectively, provide the highest and lowest overall strengths. The samples with the ferrite grains oriented in multiple directions (cases 3 and 6 in figures $4(a)$ and $(b)$, respectively) have an effective strength that is in between these two extremes. Since the multi-crystalline ferritic matrix to a certain extent approximates a poly-crystalline matrix, the effective strengths for cases 3 and 6 are close to the strength of a sample that has an isotropic ferritic matrix.

4.3.3. Influence of the grain orientation on the transformation rate. To study the effect of grain orientation on the evolution of the austenitic volume fraction, we introduce the austenitic 

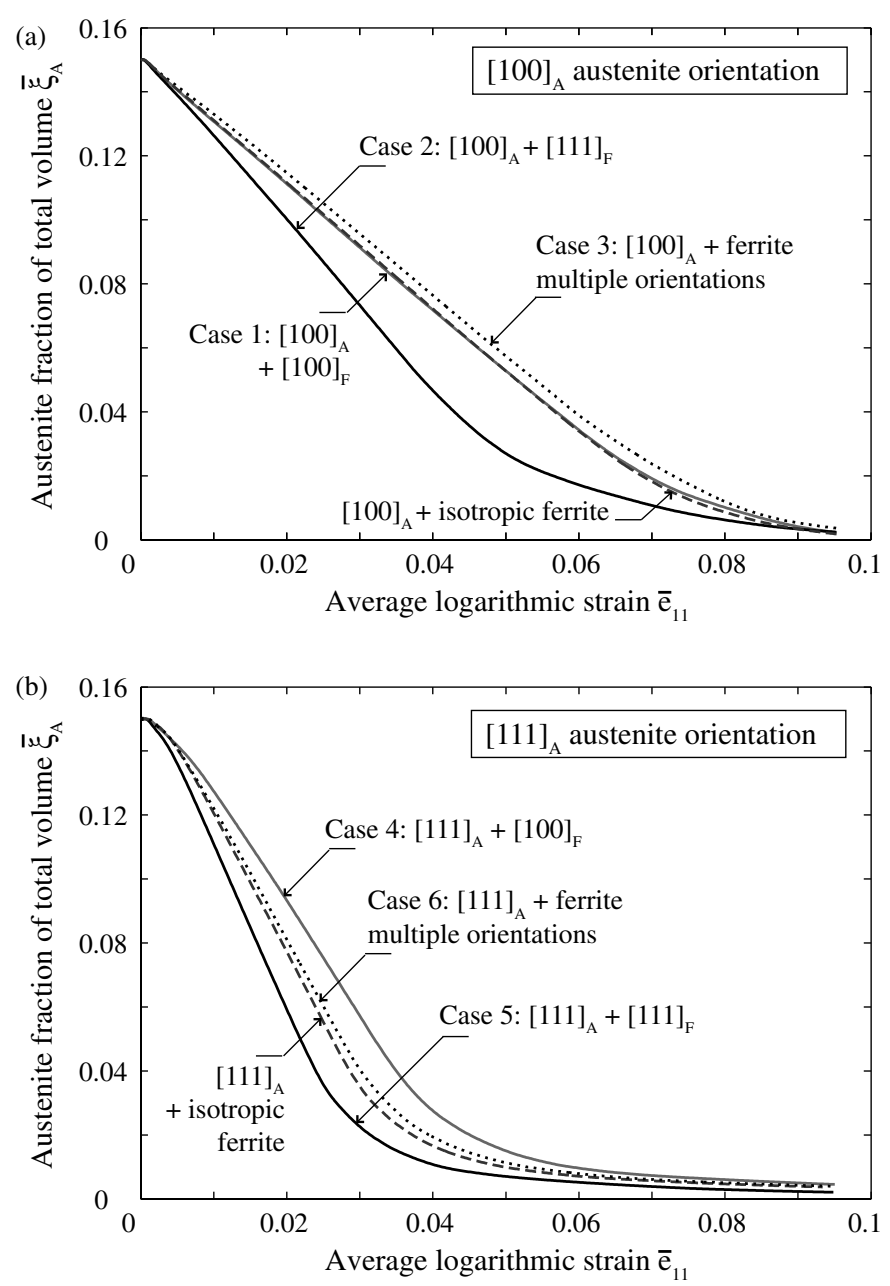

Figure 5. Average austenite volume fraction $\bar{\xi}_{\mathrm{A}}$ versus average logarithmic strain $\bar{e}_{11}$. The ferrite orientation in the samples is varied while the austenite orientation is kept constant, i.e. [100 $]_{\mathrm{A}}$ in (a) and $[111]_{\mathrm{A}}$ in $(b)$.

volume fraction averaged over the sample, i.e.

$$
\bar{\xi}_{\mathrm{A}}(t):=\frac{1}{\left|\Omega_{0}\right|} \int_{\Omega_{0}} \xi^{(0)}(\boldsymbol{x}, t) \mathrm{d} v_{\boldsymbol{x}},
$$

where

$$
\xi^{(0)}(\boldsymbol{x}, t)= \begin{cases}1-\sum_{\alpha=1}^{M} \xi^{(\alpha)}(\boldsymbol{x}, t) & \text { for } \boldsymbol{x} \in \Omega_{A} \\ 0 & \text { for } \boldsymbol{x} \in \Omega_{\mathrm{F}}\end{cases}
$$

with $\Omega_{\mathrm{A}}$ and $\Omega_{\mathrm{F}}$ the regions occupied in the reference configuration by the austenite grain and the ferrite matrix, respectively.

The evolution of the average austenite volume fraction is presented in figure 5 for a fixed orientation of the austenitic grain, which is $[100]_{\mathrm{A}}$ in figure $5(a)$ and $[111]_{\mathrm{A}}$ in $(b)$. The cases 
presented in figures 5(a) and $(b)$ correspond to those shown in figures 4(a) and $(b)$, respectively. The transformation evolution for samples with an isotropic ferritic matrix, which were reported previously in Turteltaub and Suiker [2], is depicted for comparison. When comparing the results from figures $5(a)$ and $(b)$, we observe that, regardless of the orientation of the ferrite grains, the martensitic transformation proceeds faster for samples with an austenitic grain oriented in the $[111]_{\mathrm{A}}$ direction than for samples with an austenitic grain oriented in the $[100]_{\mathrm{A}}$ direction. This result, which is in agreement with recent experimental observations in TRIP steels [37,38], can be ascribed to the fact that austenitic grains oriented in the [111] $]_{\mathrm{A}}$ direction experience a much higher stress than austenitic grains oriented in the $[100]_{\mathrm{A}}$ direction [2].

The samples with the ferritic grains oriented in multiple directions show a similar evolution of the austenitic volume fraction as the samples with an isotropic ferritic matrix. Hence, this confirms the conclusion that the matrix of six ferritic grains with different, but evenly, distributed orientations (cases 3 and 6, see table 1) already gives a good approximation of an isotropic, poly-crystalline ferritic matrix. Further, combining the results for cases 3 and 6 in figure 5 with those in figure 4 shows that a higher transformation rate increases the effective hardening capacity of the samples. This phenomenon has also been observed experimentally by Jacques et al [39], who studied the influence of the austenite transformation rate on the effective hardening capacity of TRIP steel specimens subjected to uniaxial tension. Furthermore, they observed that the transformation rate at the onset of the deformation process is relatively high but decreases strongly with continued deformation (i.e., an exponentially decaying austenitic transformation rate). This trend is confirmed by the simulation results shown in figure 5 .

\section{Concluding remarks}

In the present work, the influence of the grain orientation on the effective response of TRIP steel samples has been studied through three-dimensional finite element analyses. The TRIP steel samples are composed of a single grain of RA embedded within six grains of ferrite. Uniaxial tension simulations show that the orientations of the austenitic grain and the ferritic grain may both have a strong effect on the overall strength of the sample. The combination of austenite oriented in the $[111]_{\mathrm{A}}$ direction and a single-crystal ferritic matrix oriented in the $[111]_{\mathrm{F}}$ direction gives the highest effective strength, while the lowest effective strength is obtained from the combination of austenite oriented in the $[100]_{\mathrm{A}}$ direction and a single-crystal ferritic matrix oriented in the $[100]_{\mathrm{F}}$ direction. The effective strengths of TRIP steel samples with a ferritic matrix composed of grains with multiple orientations fall between those two extremes.

The evolution of the austenitic volume fraction and its effect on the effective hardening capacity are in good qualitative agreement with experimental observations. However, the austenite has almost fully transformed into martensite at $10 \%$ strain for all configurations studied, whereas experimental observations often indicate a remaining fraction of austenite at this deformation level. It is suggested that this difference between simulations and experiments is partly due to the absence of plasticity in the model for austenite. However, the incorporation of the plasticity in the martensitic transformation model must await a later study. Furthermore, in the present model, the carbon concentration is assumed to be uniform in the grain of RA, whereas in real materials a range of carbon concentration is to be expected. Finally, the prediction of full transformation at $10 \%$ strain may be also attributed to the absence of a harder bainitic phase in the matrix and the adoption of relatively simple grain geometries in the model. In spite of these simplifications, the results of the simulations show realistic trends and provide insight that is useful for the design of TRIP steel microstructures with improved mechanical characteristics. 


\section{Acknowledgments}

Discussions with Professor John L Bassani (University of Pennsylvania, USA) on the modelling of plastic slip in BCC single crystals and with Dr Pedro Rivera (Delft University of Technology, the Netherlands) on the metallurgical aspects of TRIP steels are gratefully acknowledged. This work is a part of the research program of the Netherlands Institute for Metals Research (NIMR) and the Stichting voor Fundameteel Onderzoek der Materie (FOM). The research was carried out under project number 02EMM20 of the FOM/NIMR program 'Evolution of the Microstructure of Materials' (P-33).

\section{References}

[1] Turteltaub S and Suiker A S J 2006 A multi-scale thermomechanical model for cubic to tetragonal martensitic phase transformations Int. J. Solids Struct. at press

[2] Turteltaub S and Suiker A S J 2005 Transformation-induced plasticity in ferrous alloys J. Mech. Phys. Solids 53 $1747-88$

[3] Jacques P J, Ladriére J and Delannay F 2001 On the influence of interactions between phases on the mechanical stability of retained austenite in transformation-induced plasticity multiphase steels Metall. Mater. Trans. A 32 2759-68

[4] Timokhina I B, Hodgson P D and Pereloma E V 2003 Effect of deformation schedule on the microstructure and mechanical properties of a thermo-mechanically processed C-Mn-Si transformation-induced plasticity steel Metall. Mater. Trans. A 34 1599-609

[5] Stringfellow R G, Parks D M and Olson G B 1992 A constitutive model for transformation plasticity accompanying strain-induced martensitic transformations in metastable austenitic steels Acta Metall. Mater. 40 1703-16

[6] Bhattacharyya A and Weng G J 1994 An energy criterion for the stress-induced martensitic transformation in a ductile system J. Mech. Phys. Solids 42 1699-724

[7] Marketz F and Fischer F D 1994 Micromechanical modelling of stress-assisted martensitic transformation Modelling Simul. Mater. Sci. Eng. 2 1017-46

[8] Marketz F and Fischer F D 1995 A mesoscale study on the thermodynamic effect of stress on martensitic transformation Metall. Mater. Trans. A 26 267-78

[9] Diani J M, Sabar H and Berveiller M 1995 Micromechanical modelling of the transformation induced plasticity (TRIP) phenomenon in steels Int. J. Eng. Sci. 33 1921-34

[10] Levitas V I, Idesman A V and Olson G B 1999 Continuum modeling of strain-induced martensitic transformation at shear-band intersections Acta Mater. 47 219-33

[11] Cherkaoui M, Berveiller M and Lemoine X 2000 Coupling between plasticity and martensitic phase transformation: overall behavior of polycrystalline TRIP steels Int. J. Plasticity 16 1215-41

[12] Suiker A S J and Turteltaub S 2005 Computational modelling of plasticity induced by martensitic phase transformations Int. J. Numer. Meth. Eng. 63 1655-93

[13] Vitek V, Mrovec M, Gröger R, Bassani J L, Racherla V and Yin L 2004 Effects of non-glide stresses on the plastic flow of single and polycrystals of molybdenum Mater. Sci. Eng. A 387-389 138-42

[14] Wechsler M S, Lieberman D E and Read T A 1953 On the theory of the formation of martensite Appl. Phys. A-Mater. 197 1503-15

[15] Ball J M and James R D 1987 Fine phase mixtures as minimizers of energy Arch. Ration. Mech. Anal. 100 13-52

[16] Duesbery M S and Vitek V 1998 Plastic anisotropy in b.c.c. transition metals Acta Mater. 46 1481-92

[17] Bassani J L, Ito K and Vitek V 2001 Complex macroscopic plastic flow arising from non-planar dislocation core structures Mater. Sci. Eng. A 319-321 97-101

[18] Hull D and Bacon D J 1984 Introduction to Dislocations (Oxford-Amsterdam: Pergamon-Elsevier)

[19] Hirth J P and Lothe J 1982 Theory of Dislocations (Malabar, FL-New York; Krieger-Wiley)

[20] Franciosi P 1983 Glide mechanisms in b.c.c. cyrstals: an investigation of the case of $\alpha$-iron through multislip and latent hardening tests Acta Metall. 31 1331-42

[21] Lee E H 1969 Elastic-plastic deformation at finite strains J. Appl. Mech. (ASME) 36 1-6

[22] Hill R and Rice J R 1972 Constitutive analysis of elastic-plastic crystals at arbitrary strain J. Mech. Phys. Solids 20 401-13

[23] Asaro R J and Rice J R 1977 Strain localization in ductile single crystals J. Mech. Phys. Solids 25 309-38 
[24] Rice J R 1971 Inelastic constitutive relations for solids: an internal-variable theory and its application to metal plasticity J. Mech. Phys. Solids 19 433-55

[25] Cuitiño A M and Ortiz M 1992 Computational modelling of single crystals Modelling Simul. Mater. Sci. Eng. $1225-63$

[26] Miehe C and Schröder J 2001 A comparative study of stress update algorithms for rate-independent and ratedependent crystal plasticity Int. J. Numer. Meth. Eng. $50273-98$

[27] Vitek V, Mrovec M and Bassani J L 2004 Influence of non-glide stresses on plastic flow: From atomistic to continuum modeling Mater. Sci. Eng. A 365 31-7

[28] Peirce D, Asaro R J and Needleman A 1983 Material rate dependent and localized deformation in crystalline solids Acta Metall. 31 1951-76

[29] Brown S B, Kim K H and Anand L 1989 An internal variable constitutive model for hot working of metals Int. J. Plasticity 5 95-130

[30] Hane K F and Shield T W 1998 Symmetry and microstructure in martensites Phil. Mag. A 78 1215-52

[31] Coleman B D and Noll W 1963 The thermodynamics of elastic materials with heat conduction and viscosity Arch. Ration. Mech. Anal. 13 167-78

[32] ABAQUS 2004 Theory Manual \& User's Manual, Volume III, Version 6.4. (Pawtucket, RI, USA: Hibbitt, Karlsson and Sorensen, Inc.)

[33] Liu X, Zhong F, Zhang J X, Zhang M X, Kang M K and Guo Z Q 1995 Lattice-parameter variation with carbon content of martensite: 1. X-ray diffraction experimental-study Phys. Rev. B 52 9970-8

[34] Anand L 2004 Single-crystal elasto-viscoplasticity: Application to texture evolution in polycrystalline metals at large strains Comput. Methods Appl. Mech. Eng. 193 5359-83

[35] Rao B V N and Rashid M S 1997 Direct observations of deformation-induced retained austenite transformation in a vanadium-containing dual-phase steel Mater. Charact. 39 435-53

[36] Sugimoto K I, Mitsuyuki K and Hashimoto S I 1992 Ductility and strain-induced transformation in a highstrength transformation-induced plasticity-aided dual-phase steel Metall. Trans. A 23A 3085-91

[37] Oliver E C, Withers P J, Daymond M R, Ueta S and Mori T 2002 Neutron-diffraction study of stress-induced martensitic transformation in TRIP steel Appl. Phys. A-Mater. 74 S1143-5

[38] Kruijver S O, Zhao L, Sietsma J, Offerman S E, Dijk N H van, Lauridsen E M, Margulies L, Grigull S, Poulsen H F and Zwaag S van der 2003 In situ observation on the mechanical stability of austenite in TRIP-steel J. Phys. IV 104 499-502

[39] Jacques P J, Furnémont Q, Mertens A and Delannay F 2001 On the sources of work hardening in multiphase steels assisted by transformation-induced plasticity Phil. Mag. A 81 1789-812 